\title{
Delos medios a la
}

convergencia

\section{La formación del espacio audiovisual ampliado en Colombia}

\section{From media to convergence The development of the expanded audiovisual space in Colombia}

\section{Da mídia à convergência A formação do espaço audiovisual expandido na Colômbia}

\section{CÉSAR MORA MOREO}

cessaremora@gmail.com - Universidad del Norte, Colombia.

ORCID: https://orcid.org/0000-0003-3343-2881

\section{ALESSANDRA PUCCINI MONTOYA}

apuccinim@gmail.com - Universidad Externado de Colombia, Colombia.

ORCID: https://orcid.org/0000-0001-5812-8152

\section{ENRIQUE URIBE JONGBLOED}

enrique.uribe@uexternado.edu.co - Universidad Externado de Colombia, Colombia.

ORCID: https://orcid.org/0000-0002-9415-7628

CÓMO CITAR: Mora Moreo, C., Puccini Montoya, A. \& Uribe Jongbloed, E. (2021). De los medios a la convergencia. La formación del espacio audiovisual ampliado en Colombia. InMediaciones de la Comunicación, 16(1), 59-85. DOI: http://doi. org.10.18861/ic.2021.16.1.3097

Fecha de recepción: 10 de septiembre de 2020 Fecha de aceptación: 26 de diciembre de 2020

\section{RESUMEN}

Este artículo da cuenta de las trasformaciones contemporáneas en materia de legislación, producción y consumo de productos audiovisuales -series, telenovelas y películas- a través de una revisión de las alteraciones, actualizaciones y cambios experimentados por los medios de comunicación en Colombia. Este análisis parte de un concepto base que entiende a los medios audiovisuales como sistemas independientes -en cuanto a los procesos de legislación, producción, distribución y consumo-, y busca mostrar los cambios que derivan actualmente en la construcción del audiovisual como un espacio común o convergente que atraviesa lo creativo, legislativo y conceptual. Se evidencia que algunos aspectos de la convergencia ya estaban presentes en la 
historia del audiovisual en Colombia, pero que se vuelven más reconocibles con la centralización dela política audiovisual contemporánea.

PALABRASCLAVE: convergencia, medios de comunicación, Colombia, entorno de medios, regulación mediática.

\section{ABSTRACT}

This article presents an account of the contemporary transformations in the matter of legislation, production and consumption of audiovisual products -series, soap operas and films- through a review of the alterations, updates and changes experienced by the media in Colombia. This analysis starts from a basic concept that understands audiovisual media as an independent system -in terms of legislation, production, distribution and consumption processes-, and seeks to show the changes that currently derive in the construction of audiovisuals as a common or convergent space that crosses the creative, legislative and conceptual grounds. It evidences that some aspects of convergence were already present throughout the history of audiovisuals in Colombia, but they become more recognizable with the centralization of contemporary audiovisual policy.
KEYWORDS: convergence, media, Colombia, media environment, media policy.

\section{RESUMO}

Este artigo dá conta das transformações contemporâneas no campo da legislação, produção e consumo de produtos audiovisuais -séries, novelas e filmespor meio de uma revisão das alterações, atualizações e mudanças vividas pelos meios de comunicação na Colômbia. Esta análise faz parte de um conceito básico que entende os meios audiovisuais como sistemas independentes -em termos de processos de legislação, produção, distribuição e processos de consumo-, e busca mostrar as mudanças que atualmente decorrem na construção do audiovisual como espaço comum ou convergente no percurso no criativo, legislativo e conceitual. É evidente que alguns aspectos da convergência já estavam presentes na história do audiovisual na Colômbia, mas que se tornaram mais reconhecíveis com a centralização da política audiovisual contemporânea.

PALAVRAS-CHAVE: convergência, mídia, Colômbia, ambiente midiático, regulação midiática. 


\section{INTRODUCCIÓN}

En el verano austral de 2020, mientras varios países exigieron el aislamiento social o promovieron que la población "se quede en casa" como estrategia para prevenir el contagio y la expansión del COVID-2019, se puso en evidencia el proceso de cambio que desde hace años tiene lugar en la relación entre nuestra sociedad y el entorno mediado por las tecnologías digitales. Por caso, mientras las salas de cine permanecen cerradas en casi todo el mundo, China se aventura a exigir que las producciones sean de más corta duración y un reestreno se convierta en un éxito masivo. Asimismo, existen productoras y distribuidoras que piensan en lanzar sus nuevas obras a través del servicio OTT (sigla en inglés de Over The Top) o darle una nueva vida en streaming a productos que se consideraban ya explotados. La situación de encierro a la que obliga la pandemia ha hecho que el televisor retorne al centro del interés de los hogares y, al menos en Colombia, los canales de televisión, el cable y los servicios de streaming lograron revitalizarse, mientras que los cines y la producción audiovisual se resintieron sensiblemente o tuvieron que reformular sus objetivos y posibilidades. Los cambios que se han producido en los diferentes aspectos del universo audiovisual, incluyendo a los conglomerados que los controlan, las formas de negociación y distribución y las nuevas plataformas y formas actuales de consumo, han reconfigurado un nuevo escenario en el plano político, creativo, organizativo y lo económico.

En este artículo se realiza un recorrido por una variedad de productos audiovisuales que sirven como eje articulador para entender los cambios antes mencionados, haciendo hincapié en el caso colombiano. Para eso se tomaron en cuenta diversas herramientas de estudio que incluyen el abordaje de las políticas públicas, el análisis de material documental y textual de productos audiovisuales y la realización de algunas entrevistas que sirven para entender los diversos procesos que han llevado a la reestructuración y cambio en la realización audiovisual, pasando de una concepción de medio, dicho en un sentido clásico del término, a una idea más cercana a la versión mcluhaniana de entorno (Roncallo-Dow, 2019), al que habremos de pensar como espacio audiovisual ampliado -de ahora en adelante, EAA- (Marino, 2016).

\section{LA NOCIÓN DE MEDIO (DE COMUNICACIÓN)}

La idea de los medios de comunicación como entes y estructuras independientes que incluían determinadas formas de producción, distribución y consumo surgió en las primeras décadas del siglo XX, algo que se extendió y sirvió para para designar a un "pequeño número discrecional de tecnologías y plataformas de comunicación: periódicos, cine, radio y televisión” (Miller \& Kraidy, 2016, p. 4). La estabilización del periódico, entre finales del siglo XVIII y transcurso del siglo XIX, adquirió relevancia y acompañó el proceso de cons- 
trucción de la idea moderna de nación (Anderson, 1983). Poco a poco, dicho fenómeno mediático adquirió una concepción de tipo comercial movido por el interés privado, erigiéndose en un elemento clave de la sociedad burguesa y el desarrollo de la esfera pública (Habermas, 1990).

Pero serían el cine y la radio los medios que se convirtieron en fenómenos capaces de atraer la atención masiva del público. De allí el creciente interés de los estudios de comunicación política para evaluar el impacto de la radio y los postulados de la Escuela de Frankfurt, o Teoría crítica, sobre el cine y, más en general, sobre la industria cultural emergente en la primera mitad del siglo XX -el término luego llevó a considerar a la idea de industrias culturales, lo cual incluyó a la televisión, la música y otras formas de expresión y comunicación (Kellner, 2020).

Aquellas primeras concepciones tendieron a pensar la aparente divergencia de los medios conforme a sus estructuras de producción, distribución y consumo, atendiendo fundamentalmente a las exigencias técnicas de cada medio y la separación empresarial de las compañías (Uribe Jongbloed, 2016). Sin embargo, desde el inicio mismo de la consolidación mediática las empresas compartían fuentes de financiación o respondían a los mismos dueños o accionistas, lo cual desestima, o al menos matiza, la idea de pensar en empresas separadas y organizadas de acuerdo a la singularidad del medio.

Este entrecruzamiento se hizo evidente a partir del surgimiento de la televisión, décadas después de que el cine ostentara ser el único medio audiovisual -primero, exclusivamente visual-. La televisión presentó por entonces una forma de producción, distribución y consumo más cercana a la radio, llevando al espacio doméstico lo que la producción cinematográfica, en tanto lenguaje audiovisual, ofrecía en las salas. Asimismo, las noticias periodísticas -los noticieros que antecedían a la proyección de las películas- abandonaron el cine y se concentraron en la "pantalla chica", fenómeno acompañado por el paulatino uso del televisor. Tiempo después, cuando los programas televisivos también fueron realizados en película fílmica, el intercambio entre la televisión y el cine incluyó el flujo de contenidos e historias narradas, además del personal que trabajaba en ambos espacios de producción. De todos modos, la relevancia social de uno y otro medio, así como las cualidades de ambos dispositivos, marcaron distancias en la forma de legislar su funcionamiento, además de la persistencia de consideraciones teóricas que señalaban las especificidades de ambos fenómenos de comunicación' 1 .

En los años 80 la cercanía entre cine y televisión se hizo mayor con el surgimiento delos canales de películas yla participación de las cadenas televisivas en la producción cinematográfica en Estados Unidos. En ese marco, la aparición

1 La especificidad de dichos fenómenos comunicativos establece diferencias evidentes que llevaron a que Marshall McLuhan (1994), por ejemplo, estableciera, en la década del 60, diferencias ligadas al volumen y tipo de información del cine y la televisión. De allí que el cine fuera considerado un medio caliente -saturado de información-y la televisión como un medio frío, dado el carácter más bien táctil adjudicado por McLuhan. 
del videocasete transformó la grabación para posterior emisión, cambiando incluso la forma de trabajo de los artistas y directores, abriendo nuevas posibilidades creativas y modificando los modos de consumo de películas y otros materiales audiovisuales. En tal sentido, el video grabado implicó, en principio, una nueva forma de distribución de la producción cinematográfica, y después se convirtió en una suerte de ambiente propio que abrió la existencia y posibilidades de los canales comunicativos existentes.

El videocasete permitió practicar otros modos de ser audiencia y gestó, además, lo que Jenkins (2006) caracterizó como la cultura de la remezcla, ya que emergieron herramientas de producción y distribución para un público ampliado. Si bien la disminución de los costos de producción del cine en $8 \mathrm{~mm}$ y $16 \mathrm{~mm}$ había permitido, algunos años antes, un proceso similar que favoreció la aparición de cineclubes y la producción de los documentalistas, los sistemas de copia de películas cinematográficas seguían siendo dificultosos y no llegó a posibilitar una ampliación de los consumos como la que permitió el video.

La legislación, sin embargo, se mantenía enfocada en la separación conceptual de esos espacios de contacto ligados al cine, la televisión y el video y, en términos valorativos, implicó incluso la proliferación de discursos elitistas que privilegiaron al cine como arte y veían a la televisión y al video como mero entretenimiento hogareño. Esta percepción a favor del cine, al que también se había calificado, en sus primeras décadas de desarrollo, como una mercancía masiva sin valor artístico -se recuerdan y debaten todavía las derivaciones de lo postulado por Benjamin, 1989)-, llevó a que la premiación de los productos cinematográficos se convirtieran en el epítome del valor cultural. Tensión que, haciendo un breve salto al presente, parece actualizarse con la evidente molestia que señalan algunos directores de cine ante la aparición de obras que han sido directamente desarrolladas para plataformas OTT y llegan a convertirse en el foco de atención de los viejos festivales cinematográficos, evidenciando una valoración estética arraigada en la nostalgia por la técnica. "La revolución que estamos viviendo es apabullante. Todo está cambiando... Para mucha gente ya es normal ver una película en el celular, en un iPad" (Vallejo, 2018, p. 127), manifestó el director mexicano Ernesto Contreras en el marco de los premios recibidos por Roma, película ganadora del Premio Óscar 2019 como Mejor Película Extranjera-además del galardón obtenido por Alfonso Cuarón(2018) como Mejor Director-. El debate, por supuesto, no se reduce a ese diagnóstico preciso, a la vez que desconcertado, de Contreras, pero sirve para mostrar el momento de cambio que se experimenta en la actualidad.

Con la llegada de Internet en los años 90 y la facilidad de los procesos de digitalización comenzaron a desvanecerse algunas de las diferencias entre la producción de cine, televisión y video y se capitalizó el desarrollo de este último, extendiendo y expandiendo el número de posibilidades de producción y reproducción, mezcla y remezcla. La piratería practicada en la era del video 
se multiplicó masivamente con la digitalización y se convirtió en una de las mayores formas de acceso a la producción local, regional, nacional y mundial (Mattelart, 2009). En esa misma lógica de la piratería subyace el éxito del mercado informal de distribución dela producción audiovisual de Nollywood, más cercana a la televisión que al cine en su estética (Lobato, 2010) y, también, todo lo que refiere a la precariedad laboral que caracteriza sus modos de producción (Obiaya, 2012). Asimismo, ylejos de convertirse en la idealización de una suerte de anarquía que vendría a democratizar la producción cultural, la piratería fue domesticada en buena medida por la industria audiovisual internacional a través de la revolución del streaming (Fredriksson, 2020). Simultáneamente a las líneas que se fueron desdibujando entre el video, el cine y la televisión, las compañías mediáticas mundiales empezaron hace algunos años a concentrar la propiedad de los diversos tipos de medios y algunas de las empresas mediáticas nacionales se diversificaron en una expansión que implicó estrategias empresariales de tipo vertical y horizontal (Fox \& Waisbord, 2002).

Esta nueva convergencia, de tipo económico, que tomó impulso a partir de los años 80 cuando el Reino Unido y Estados Unidos desestimaron y buscaron evadir los lineamientos impulsados por el Nuevo Orden Mundial de la Información y la Comunicación (NOMIC) (Mattelart \& Mattelart, 1997), el cual se enmarcaba en la Organización de las Naciones Unidas para la Educación, la Ciencia y la Cultura (UNESCO, por su traducción al inglés) y, tal lo señalado en el conocido Informe MacBride, instó a realizar cambios que permitieran regular y equilibrar los flujos de información entre los distintos países. El desconocimiento de estos propósitos por parte de ambas potencias mundiales terminó por consolidar, paulatinamente, el dominio actual de unas pocas corporaciones que manejan la cadena de producción, distribución y consumo audiovisual, lo cual limita la producción local y promueve la explotación de los trabajadores del sector a escala planetaria (Miller, 2020).

Este proceso, que desde un inicio ha buscado la convergencia en términos de capitalización, usufructo del talento humano, comercialización y nuevas formas de producción, distribución y consumo, hace difícil reconocer las separaciones de los medios, tal como se expresaba hace algunas décadas. La película Mulan, dirigida por Niki Caro (2020), es un caso ejemplar del proceso que se está viviendo: previsto su estreno en salas de cine, finalmente se distribuyó a través de la plataforma Disney+, decisión que causó malestar entre algunos sectores de la industria audiovisual debido al impacto económico sufrido por los encargados, tradicionalmente, de proyectar las películas (Rivera, 10 de agosto de 2020), y más allá de que exista el atenuante de que los cambios responden a la situación pandémica vivida desde comienzos de 2020. El caso de China ilustra estos componentes de la realidad actual, ya que la reapertura de las salas de cine que tuvo lugar hace algunos meses salas de cine implicó no solo la protocolización del cuidado de la asistencia, sino también de pautas 
que implicaron que la proyección no supere las dos horas de duración. En tal sentido, el reestreno de Harry Potter and the Philosopher's Stone, dirigida por Chris Columbus (2001), generó ganancias que superaron los mil millones de dólares de recaudación (Redacción La Vanguardia, 18 de agosto de 2020), así como resultó económicamente impactante la premiere de Tenet, película de Christopher Nolan (2020), estrenada pese a que su duración pasa las dos horas reglamentadas (Rubin \& Davis, 2020).

Otro ejemplo lo ofrece la versión de la película Justice League que Zack Snyder no pudo concluir. Si bien el film se terminó bajo la dirección de Joss Whedon (2017), existe desde hace meses una apuesta más del servicio de streaming-HBO Max en este caso-, en este caso apalancada por una estrategia mediática que incluye el uso de Twitter, a través de la etiqueta \#ReleasetheSnyderCut [\#LiberenElCorteDeSnyder], para que los fans demanden y finalmente puedan ver el proyecto inconcluso de Snyder. Si bien se espera que esa versión sea conocida en la primera mitad de 2021, la demanda ha generado el rumor de que la versión será finalmente dividida en episodios, como si se tratara de una serie de televisión que buscaría capitalizar la promoción y expectativa despertada (Kit, 2020).

En la actualidad, si tomamos en cuenta las serializaciones de las producciones audiovisuales contemporáneas, la equivalencia técnica que muestran las producciones para cine o televisión y el cruce constante de las empresas que participan en esos espacios de la realización audiovisual ya no deja rastro de las viejas diferencias que ligaban a un producto con un medio específico. Incluso las salas de cine, que antes estaban dedicadas a la proyección casi exclusiva de películas, hoy transmiten opera o ballet en vivo, exhiben visitas a museos y permiten disfrutar partidos de fútbol. Parafraseando -o mejor, tergiversando-a Scolari (2013b): ¿podemos seguir definiendo estas prácticas de consumo audiovisual como "ver cine"? (p. 27). Si a esto le agregamos la proliferación de dispositivos como las tablets o los canales de YouTube que ofrecen la visualización de videojuegos en acción, puede señalarse un cambio fundamental de interfaz (Scolari, 2013a), aunque se siga consumiendo producción audiovisual.

Más allá de estas mutaciones y el hecho de que los medios se han amalgamado o, al menos borroneado, las singularidades del entorno mediático característico de la segunda mitad del siglo XX, la reglamentación y la legislación dedicada a regular el área audiovisual mantuvieron las diferencias entre los distintos espacios, lo cual permitiço que, al menos de manera ilusoria, estos medios siguieran teniendo una existencia paralela. La legislación nacional e internacional en materia de políticas culturales se mantuvo durante mucho tiempo en esa línea, y el desarrollo de las nuevas tecnologías ha hecho que, en algunos casos, muestre cierta contradicción con las realidades experimentadas por los usuarios y los consumidores del audiovisual. 
Finalmente, es clave señalar la centralidad que sigue teniendo el Estado, aunquesu rolen buena medidahaya pasado dela regulación, el controlyla protección delaproducción audiovisuala la tarea de "mediador, facilitadory promotor delas industrias mediáticas" (Miller \& Krady, 2016, p. 80). Es por eso que el concepto de sistemas mediáticos nacionales mantiene su relevancia, en particular para el estudio comparativo de prácticas e instituciones (Flew \& Waisbord, 2015). En este artículo, y con el objetivo de ilustrar las situaciones antes mencionadas y hacer, de alguna manera, ese desplazamiento que va de los medios - pensados como entidades separadas- al actual espacio audiovisual ampliado (Marino, 2016) ${ }^{2} \mathrm{o}$ convergente (Deuze,2007), se propone seguir un recorrido por los lindes del cine, la televisión y el video en Colombia, dando cuenta de sus interacciones y la relación con las políticas públicas culturales que sostuvieron las transformaciones.

\section{EL CASO COLOMBIANO}

El punto de partida para realizar el recorrido es la producción audiovisual colombiana de los años 60 del siglo XX. Luego se establecen una serie de cortes esquemáticos que marcan la transición entre los años 90 y la primera década del siglo XXI y, finalmente, al EAA colombiano que se fue conformando en los últimos años. Las fuentes utilizadas incluyen documentos y entrevistas que se detienen en esa historia y los acontecimientos destacados del campo audiovisual de Colombia, además de la revisión de las leyes y decretos que delinearon las políticas culturales y mediáticas.

\subsection{Medios claramente diferenciados (1960-1980)}

La conformación del Instituto Nacional de Radio y Televisión (INRAVISIÓN), a partir del Decreto No 3267 de 1963, estableció un sistema mixto entre actores públicos y privados, dejando a este último sector el manejo de la programación televisiva conforme a la realización de licitaciones y destinada, por entonces, al único canal de televisión existente: Canal 1 (Calero Aparicio, 2002). Cuatro más tarde, en 1967, nació el canal Teletigre, que luego pasaría a ser la segunda cadena nacional: Cadena 2 (Banrepcultural, 2020). Años antes, la negociación entre Fernando Restrepo, director por entonces de Radio Televisora Nacional de Colombia, y Goar Mestre, un productor cubano representante en América Latina de la cadena estadounidense CBS, permitió que Colombia cuente con su propio telecine, un aparato requerido para convertir películas cinematográficas al formato televisivo para transmitir contenidos audiovisuales en la "pantalla chica". Esto significó un cambio trascendental en la forma de hacer televisión, que hasta 1958 era completamente en vivo (Señal Memoria. Redacción RTVC, 2 de agosto de 2018).

2 Definido como el "conjunto integrado por los sectores del cine, la televisión abierta y de pago (analógica y digital) y los servicios online” (Marino, 2016, p. 12). 
La década del 70 se caracterizó por la creación del canal educativo Canal 11, la inauguración de una estación de Telecom en el municipio de Chocontá -que permitió que la televisión nacional se incorporara a la red mundial de transmisión por satélite y se pudieran ver programas de televisión extranjeros en directo-, y la concesión de licitaciones a las programadoras RTI, Punch, Caracol, Protón, Alberto Dangong Uribe, Eduardo Ruiz Martínez, Jorge Barón y Alberto Acosta, entre otros actores que operaron en los inicios dela producción audiovisual colombiana (Redacción El Tiempo, 11 de junio de 2004). Durante esos años también fue creada la Compañía de Fomento Cinematográfico (FOCINE), una entidad del Estado que tuvo la tarea de apoyar el desarrollo de producciones nacionales, además de que buscó convertir a Colombia en un escenario atractivo para la filmación de los proyectos de las grandes productoras extranjeras y generar beneficios económicos para el país.

Hasta ese momento las diferencias entre cine y televisión eran muy marcadas, tanto en el terreno de la producción como a nivel conceptual y legislativo. Por un lado, el trabajo cinematográfico se caracterizaba por su precariedad (Uribe Jongbloed \& Miller, 2020) y las dinámicas de intercambio entre ambos medios se limitaban a la participación actoral de algunos artistas, como fue el emblemático caso de Carlos "El Gordo" Benjumea, quien participó en la serie televisiva Yo y tú, lanzada en 1956, y en la película El taxista millonario, de Gustavo Nieto Roa (1979), un éxito de taquilla sin precedentes que se mantuvo en el primer puesto hasta 1981 con 542,000 dólares de recaudación (Triana de Vargas, 1982). En este periodo la televisión gozó de un crecimiento notable en términos técnicos, algo que el propio Benjumea reconoció en una entrevista realizada en 2014:

\footnotetext{
Nosotros pasamos de tener una televisión artesanal y romántica a volvernos una industria de la televisión. Ese es el cambio realmente, ahí está todo el cuento. Entonces aparecieron personas que les enseñaron a los nuevos cómo se escribe, cómo se hace, cómo se pone la cámara, cómo se ilumina, no cómo se alumbra sino ¡cómo se ilumina! Cómo se pone sonido, no cómo se hace ruido. Cada tema empezó a volverse algo que requería especialización y así llegamos e intentamos hacer las cosas en los años 80 (Carlos Benjumea en Mora Moreo, Uribe Jongbloed \& Puccini Montoya, 2014).
}

Sin embargo, las condiciones laborales mostraban la falta de garantías para los artistas, quienes eran contratados por episodio, lo cual caracterizó la inestabilidad laboral del periodo (Redacción Radio Nacional de Colombia, 13 de junio de 2019).

Otro caso emblemático de esta etapa lo representa el periodista Daniel Samper Pizano, autor durante años de las columnas humorísticas Dejémonos de vainas, insumo de la serie televisiva que llevó el mismo nombre y se emitió, desde 1984, por más de una década. Asimismo, Samper Pizano estuvo in- 
volucrado en otras series como Don Camilo, de 1987, que lo obligó a arduas negociaciones en Italia dada la raíz literaria y cinematográfica del personaje creado por el escritor Giovannino Guareschi, Escalona, emitida en 1991, y Leche, producción de 1996; además de ser el padre de Daniel Samper Ospina, periodista que en 2016 se convirtió en youtuber; una muestra anecdótica de la creciente migración a otros formatos digitales.

A mí me encantó la historia desde un principio, algunos de los episodios me impresionaron. Cuando mi mamá vio mi fascinación por Don Camilo y empezaron a llegar las películas con Fernandel (nombre artístico del actor francés: Fernand Joseph Desiré Contandin), ella me llevó a verlas. Fue la primera vez que vi una imagen de Don Camilo distinta a la que yo tenía (Daniel Samper Pizano en Mora Moreo, Uribe Jongbloed \& Puccini Montoya, 2016).

Por otro lado, en medio del auge y el impacto mediático de la televisión, a medidos de los años 80, se produjeron otras disposiciones reglamentarias. En 1985 apareció la antena parabólica, lo que implicó una mayor penetración del servicio televisivo en zonas que, debido a las condiciones geográficas del país, no podían tener fácil acceso (Mejía Reyes, 2006). Esto también fue clave para la aparición de canales comunitarios y permitió que se puedan ver programas de la televisión satelital abierta de otros lugares del mundo. En esa misma época, durante la presidencia de Belisario Betancur, TV Cable LTDA se convirtió, en 1987, en la primera operadora de suscripción por cable en Colombia. Esta sociedad fue fundada por la empresa Datos y Mensajes - una de las programadoras más destacadas de la época perteneciente a la familia del expresidente Misael Pastrana-, en sociedad con El Tiempo, RTI, RCN Televisión y Caracol Televisión (Redacción El Tiempo, 11 de junio de 2004). El dato anterior señala, además, la consolidación temprana de los oligopolios dentro de la industria, apenas dos años después de que se aprobara la Ley No 42 de $1985^{3}$ que contemplaba la posibilidad de que particulares prestaran servicios de televisión por suscripción (Bernal \& Dávila, 1999).

En ese proceso también tuvo lugar cierta descentralización dela televisión a partir del nacimiento de los canales regionales, muchos de ellos reproductores de los contenidos de lo producido en las grandes ciudades de Colombia, pero gestores de miradas que permitieron mostrar las singularidades y las manifestaciones culturales de las distintas regiones del país. En 1986, Teleantioquia fue el primer canal regional en establecerse en el noroeste de Colombia, seguido por Telecaribe, ese mismo año, y Telepacífico, en 1988 (García, 2012).

Al cierre de la década del 80, la expansión de los espacios de distribución y el consumo de la producción audiovisual, la emergencia de los clubes de alquiler de videocassettes, la instalación de nuevos canales públicos y el auge de

3 Véase: Ley No 42 (1985) sancionada por el Congreso de la República de Colombia. Recuperado de: http://www. suin-juriscol.gov.co/viewDocument.asp?id=1597337 
la televisión vía satélite y el sistema de cable, a lo que se agrega cierto despegue del cine promovido por FOCINE, puede entenderse como una expresión de la diversidad audiovisual en expansión.

\subsection{Las amalgamas y los conglomerados (1990-2010)}

El periodo comprendido entre inicios de 1990 y finales de la primera década del siglo XXI se destacó por un desarrollo considerable en materia de legislación dedicada al sector audiovisual. La flamante Constitución de 1991 implicó un punto de partida para las expectativas de cambio que se darían en la industria durante las siguientes décadas. Antes, el Decreto No 1900 del año $1990^{4}$ y la Ley No 14 sancionada en $1991^{5}$ habían sentado algunas bases legales y administrativas para la regulación integral del servicio de televisión. Dichas leyes apostaban a desestimular la concentración monopólica de las grandes programadoras televisivas, regular la participación estatal y mejorar la calidad del servicio a partir del estímulo a la competencia (Redacción El Tiempo, 16 de diciembre de 1990). No obstante, y pese a que el decreto y ley mencionados hacían mención al control y la vigilancia del Estado, también le abrían paso a la competencia en tanto signo de una época neoliberal marcada por la apertura de la producción y la distribución televisiva a las dinámicas globales que presentaba el sector de las telecomunicaciones (Bernal \& Dávila, 1999).

Mientras la televisión avanzaba hacia una normatividad que conciliaba lo público y lo privado, luego de los proyectos de ley fallidos de 1989 y 1990 (Vizcaíno, 2004), FOCINE fracasaba en su estrategia para atraer capital extranjero, en parte, según Rivera Betancur (2019), por la ola de violencia que sufría el país. En ese contexto, FOCINE dejó de existir en 1993, paradójicamente un tiempo después de que Rodrigo D. No futuro, de Víctor Gaviria (1990), fuera escogida como la primera película colombiana selecciona por el Festival de Cannes y sin que haya terminado la producción de su último proyecto, la película $L a$ estrategia del Caracol, dirigida por el cineasta Sergio Cabrera (1993), tiempo después nominada a los Premios Goya (Guzmán, 21 de octubre de 2018). Un tiempo de recambio y ajustes que, desde el punto de vista de los cruces entre video, televisión y cine, tiene su expresión en una imagen de la película de Cabrera: en una escena se muestra al Doctor Holguín, personaje interpretado por Víctor Mallarino, quien se dirige a su subalterno mediante videos pregrabados proyectados en un televisor, a pesar de que ambos se encuentran en la misma habitación.

En ese marco, la Constitución de 1991 planteó la creación de la Comisión Nacional de Televisión (CNTV), que a partir de entonces sería la encargada de

4 Véase: Decreto No 1900 (1990), Presidencia de la República, Colombia. Recuperado de: https://www.mintic.gov. co/portal/604/articles-3568_documento.pdf

5 Véase: Ley No 14 (1991), sancionada por el Congreso de la República de Colombia. Recuperado de: https://www. funcionpublica.gov.co/eva/gestornormativo/norma.php?i=266 
la reglamentación del servicio de televisión en Colombia, cuyo marco jurídico estuvo consignado en la Ley $\mathrm{N}^{\circ} 182 \mathrm{de} 1995^{6}$. La CNTV se caracterizó por ser un órgano autónomo e independiente del poder ejecutivo nacional, que en teoría permitió un ejercicio más democrático del sistema de prestación del servicio televisivo. Sin embargo, el desarrollo tecnológico y el fenómeno de convergencia digital que habilitó que los diversos servicios (conexión a Internet, sistema de televisión y telefonía, difusión radiofónica) fueran prestados a través de una misma red, hizo que la eficiencia del mencionado modelo regulatorio comenzó a ser cuestionado, dado que la regulación generó incoherencias entre los distintos órganos de control (Pacheco, 2015). Asimismo, mediante esta misma legislación, modificada en 1996, se abrió el camino para la creación de los canales privados, Caracol y RCN entre ellos, y comunitarios.

La Constitución también permitió que en 1997 se instituyera el Ministerio de Cultura y la Dirección de Cinematografía, que permitió que años más tarde se promulgara la Ley No 814 de $2003^{7}$, o Nueva ley de cine, que estimuló la producción local a través de beneficios tributarios para las empresas que inviertan en la realización cinematográfica; en ese contexto se creó el Fondo para el Desarrollo Cinematográfico (FDC),

una entidad autónoma regida por el derecho privado cuyo objetivo es el fomento y la preservación del patrimonio colombiano de imágenes en movimiento, así como de la industria cinematográfica colombiana. Este nuevo Fondo recibe los bienes que fueron de FOCINE y, para sus actividades, añade a su nombre la denominación Proimágenes en Movimiento (Ministerio de Cultura, 2010, p. 505).

Como antes se deslizó, durante la década del 90 la industria audiovisual colombiana ya contaba con producciones televisivas y cinematográficas de reconocimiento. Entre estas se encuentran la telenovela Café con Aroma de Mujer, de 1994), que se convirtió en el primer gran éxito de venta internacional; Amar y vivir, del año 1988), cuyo éxito motivó la realización de una película y, más de veinte años después, en 2020, se concrete una nueva versión distribuida por Netflix; y la película La vendedora de rosas, de Víctor Gaviria (1998), obra que retrató la dura realidad que viven muchos niños sumidos en la pobreza en Medellín y, en 2015, recobró el impulso inicial gracias a la exitosa serie de televisión Lady, la vendedora de rosas, basada en la vida de Lady Tabares, la actriz protagónica de la película.

Por su parte, el éxito que a partir 1994 cosechó la telenovela Café, con aroma de mujer en los mercados de Europa del Este e Israel sentaron las bases para la

6 Véase: Ley No 182 (1995), sancionada por el Congreso de la República de Colombia. Recuperado de: https://pdba. georgetown.edu/Parties/Colombia/Leyes/Ley182.pdf

7 Véase: Ley No 814 (2003) sancionada por el Congreso de la República de Colombia. Recuperado de: https://www. funcionpublica.gov.co/eva/gestornormativo/norma.php? $\mathrm{i}=8796$ 
venta internacional de Yo soy Betty, la fea, obra de 1999 que se convertiría en la gran producción colombiana en el exterior, con más de veinte adaptaciones y emitida en cerca de 70 mercados mundiales (Uribe Jongbloed \& Diez, 2017). Vale destacar que el desconocimiento de $\mathrm{RCN}$ en este tipo de negociaciones llevó a que "los derechos de adaptación de Betty se vendieran de diferentes maneras a distintos compradores -en ocasiones, solo se vendía el guion, otras veces se vendía el guion más un libro de producción" (Uribe Jongbloed \& Diez, 2017, p. 105). A modo de anécdota, aunque delata el impacto nacional de la telenovela, vale mencionar que Andrés Pastrana, entonces presidente de Colombia, llamó a los directivos de RCN para evitar que el personaje de Betty aceptara un soborno o se mostrara involucrada en hechos de corrupción que, tal se desprende del llamado presidencial, sería desmoralizante parala sociedad (Redacción Publimetro Colombia, 19 de julio de 2019).

Además de los canales abiertos privados de alcance nacional, en esos años entraron en funcionamiento canales privados regionales en ciudades como Yopal, Pereira y Bogotá. Por caso, en 1999 la CNTV le adjudicó a la Casa Editorial El Tiempo -dueña del periódico nacional del mismo nombre- el canal bogotano Citytv. Mientras que algunas programadoras como Punch, JES y Cenpro entraron en crisis y desaparecieron al no contar con fuentes de financiación y un contexto marcado por la crisis del modelo neoliberal. En 2003, la CNTV, con la intención de fortalecer a la televisión pública, le adjudicó cuatro concesiones a Canal 1, un año antes de que INRAVISIÓN fuera liquidada y sustituida por Radio Televisión Nacional de Colombia (RTVC) (Banrepcultural, 2020).

Simultáneamente, y tras años de abandono a la industria cinematográfica, la Nueva ley de cine apostó a generar un ambiente en el que la realización audiovisual dejara de ser prohibitiva en lo económico y las potenciales ganancias generaran aportes para el crecimiento dela industria (Tenorio, 2017). Transcurrida una década de la promulgación de la ley se evidenciaban signos positivos relacionados al incremento de la producción nacional y el reconocimiento de varias películas en festivales internacionales, aunque la recaudación por los ingresos de taquilla no mostró en esos años incrementos significativos (Rivera Betancur, 2014).

En 2008, producto en gran medida de los procesos de apertura del mercado y el proceso privatización favorecidos por la Constitución (Matías, 2006), Telmex compró las operaciones de televisión por suscripción de TV Cable Bogotá, Cablecentro, Superview, Teledinámica y Cablepacífico, y se convirtió así en el mayor operador de televisión por cable del país. Un año después, se produjo la compra parcial e internacionalización de algunas productoras nacionales: NBC Universal invirtió en RTI, Fox de News Corporation paso a ser dueño de Telecolombia y Sony Pictures compró acciones de Teleset. Procesos que evidencian que Colombia no es ajena a la tendencia que permitió la creación de 
grandes conglomerados y oligopolios mediáticos, con el consecuente riesgo de que se detenga la producción local y regional y se angosten las posibilidades de democratizar la circulación de mensajes.

Para entonces resultó evidente el crecimiento de la cobertura de Internet, que entre 2000 y 2008 pasó de menos del 5\% a un 25\% de la población colombiana (Arango Forero et al., 2009). Dicho crecimiento está atado a un elemento importante del periodo: la sanción de la Ley No 1341 de 2009 por la cual se definieron los "principios y conceptos" que regirían a la sociedad de la información y se fijó la organización de las Tecnologías de la Información y las Comunicaciones (TICs) ${ }^{8}$. Además, se creó la Agencia Nacional del Espectro y se dictaron otras disposiciones que hicieron, desde el punto de vista nominal, que la Comisión Reguladora de Telecomunicaciones (CRT) pase a llamarse Comisión Reguladora deComunicaciones(CRC).La misma quedó encargada, entre otras funciones y como órgano del flamante Ministerio de Tecnologías de la Información y las Comunicaciones (MinTICs), de promover la competencia de las telecomunicaciones, evitar la formación de monopolios y regular los mercados de las redes y los servicios de comunicaciones.

De esta manera quedaron diferenciados los tres entes encargados de la supervisión de las distintas formas de distribución de la producción audiovisual: el cine quedó en manos del Ministerio de Cultura, la televisión pasó a estar controlada por la CNTV e Internet por la CRC-MinTICs.

\subsection{El espacio audiovisual ampliado (2010-2020)}

Netflix llegó al país en septiembre de 2011 (El Espectador, 9 de septiembre de 2011), y en un contexto en el que aún no se contemplaba, en materia legislativa, la regulación de las plataformas de streaming. Fue así que, de manera algo tardía e insuficiente respecto de los cambios que en materia de convergencia tecnológica se estaban experimentando en la regulación del servicio público de televisión en Latinoamérica, el gobierno de Colombia liquidó la CNTV y creó la Autoridad Nacional de Televisión (ANTV). Por su parte, para competir con estas plataformas, los canales privados como Caracol Televisión desarrollaron servicios de streaming en las que comenzaron a alojar telenovelas, series, películas y eventos en vivo, como los partidos de fútbol (Pacheco, 2015).

El mismo año en que la ANTV asumía las funciones de la CNTV fue sancionada la Ley № 1556 de $2012^{9}$, conocida como Ley de filmación de Colombia, que diseñó un paquete de beneficios tributarios para las productoras internacionales que decidieran filmar en Colombia, locual pretendía impactaryatraer "producciones fugitivas" (runaway productions) como Narcos de Netflix o la

8 Véase: Ley No 1341 (2009), sancionada por el Congreso dela República de Colombia. Recuperado de: https://www. mintic.gov.co/portal/inicio/3707:Ley-1341-de-2009

9 Véase: Ley No 1556 (2012), sancionada por el Congreso de la República de Colombia. Recuperado de: http://www. cancilleria.gov.co/sites/default/files/tramites_servicios/visas/archivos/ley_1556_de_2012.pdf. 
más reciente, de 2019, Gemini Man. En sus inicios esta ley estaba dirigida a las obras cinematográficas, sin excluir a las películas producidas para televisión u otros medios, y debían cumplir con las consideraciones establecidas por el Comité para la Promoción Fílmica de Colombia. Al respecto, uno de los trabajadores de la industria audiovisual entrevistado en el marco de la investigación realizada planteó que

cuando se habla de la Ley № 1556 se enfoca mucho en proyectos cinematográficos, pero ¿qué es un proyecto cinematográfico si ya no tenemos cine y todo es digital? Entonces sucedió que nos encontrábamos trabajando en la producción de alguna serie, aunque para nosotros era un proyecto cinematográfico, pero la norma marcaba diferencias al respecto. Entonces, claro, entender qué era cine para la ley de cine ha sido muy chistoso, ya que teníamos un proyecto audiovisual como una serie, que tiene muchos más ingresos, pero que no era considerado cine por el hecho de tener capítulos ${ }^{\mathbf{1 0}}$.

En ese marco, la serie Narcos llevó a replantear, en 2015, qué formatos audiovisuales podrían acceder a los beneficios promovidos por la legislación, ya que dicha serie recibió los apoyos derivados de la Ley de filmación de Colombia presentándose como una película para televisión, aunque la aparente contradicción - por ser una serie- motivó que años más tarde se creara el Plan Nacional de Desarrollo que extendió los beneficios de la ley a "otros géneros audiovisuales realizados en Colombia"11.

La llegada de las "producciones fugitivas", cuyos trabajadores se encuentran usualmente sindicalizados, también ha permitido que los trabajadores colombianos experimenten mejores condiciones laborales y demanden por sus derechos:

En televisión trabajamos en jornadas muy extensas, estamos hablando de 15, 16 y hasta 18 horas. [En contraste] las producciones extranjeras que han venido están acostumbradas a trabajar la cantidad de horas laborales mínimas que corresponde. Es muy beneficioso para los que trabajamos en este tipo de producciones, porque se habla de un horario y generalmente vamos a trabajar 12 horas, pero con ellos trabajamos 9 horas u 8 horas. En las producciones extranjeras se cumplen casi con todos los parámetros exigibles ${ }^{12}$.

No obstante, declaraciones como las de Ana María Orozco, protagonista de Yo soy Betty, la fea, expone otros aspectos debatidos en Colombia: los derechos

10 Testimonio obtenido en la Entrevista No 11 . Las entrevistas aquí citadas forman parte del proyecto de investigación denominado "Condiciones yexpectativas delos trabajadores del audiovisual a partir dela Ley 1556". Dicho proyecto fue ganador del estímulo de "Investigación en Cinematografía" del Fondo para el Desarrollo Cinematográfico (FDC) en 2019.

11 Véase: Presidencia de la República, Colombia (2018). Recuperado de: https://id.presidencia.gov.co/ especiales/190523-PlanNacionalDesarrollo/documentos/BasesPND2018-2022.pdf

12 Testimonio obtenidoen la Entrevista No 16 del proyecto de investigación denominado "Condiciones yexpectativas de los trabajadores del audiovisual a partir de la Ley 1556". 
de los artistas de recibir ingresos por las retransmisiones de los productos audiovisuales, más allá del pago que reciben por el uso de la imagen (Redacción WRadio, 1 de agosto de 2019). En tal sentido, y con la finalidad de proteger a los trabajadores del sector, en 2017 se aprobóla Ley $\mathrm{N}^{\circ} 1835^{\mathbf{1 3}}$, una norma que tiene como objetivo el reconocimiento de las regalías a los directores y los guionistas por la reproducción de sus obras.

También en 2017, en pleno proceso de convergencia mediática, los Premios India Catalina de la Televisión Colombiana pasaron a llamarse Premios India Catalina de la Industria Audiovisual, un guiño al dinamismo actual del sector y la necesidad de incluir a las series y los documentales web como parte del EAA (Colprensa, 19 de diciembre de 2016). Por caso, la serie Déjala morir, emitida en 2017 por el canal regional Telecaribe, se convirtió en la producción más premiada de la edición 2018 con 13 premios India Catalina de la Industria Audiovisual. Durante estos años también se estrenaron Distrito Salvaje, en 2018, la primera producción colombiana para Netflix (Redacción Caracol Radio, 26 de septiembre de 2018) y Bolívar, de 2019, una serie de Caracol Televisión distribuida inicialmente a través de Netflix en Estados Unidos y América Latina, excluyendo a Colombia, y transmitida en el país cinco meses después por televisión abierta (Pardo, 5 de julio de 2019). Realizaciones que expusieron el modo en que se fueron desdibujando los límites entre los distintos medios y espacios de distribución de contenidos.

Luego de siete años de la creación de la ANTV y la Ley No 1556 (Ley de filmación de Colombia), se acordó una legislación acorde con las dinámicas de convergencia: con la Ley No 1978 de $2019^{14}$, conocida como Modernización del sector de Tecnologías de la Información y las Comunicaciones, la televisión pública dio un paso fundamental al universo multiplataforma. A partir de allí la Comisión de Regulación de las Comunicaciones (CRC) asumió las funciones de la ANTV (Redacción Gov.Co, 25 de junio de 2019), lo cual denota también que los temas relacionados a la convergencia quedaron bajo la órbita de un ministerio, el MinTICs, enfocado más bien en la tecnología, sin contemplarse el aspecto cultural involucrado en la producción audiovisual.

Por otro lado, en 2019 las salas de cine alcanzaron una cifra récord de 73,1 millones de espectadores, logrando un "incremento de 9 millones de espectadores adicionales a los registrados en 2018" (Proimágenes Colombia, 2020, p. 4). En cuanto a las formas de consumo de contenido audiovisual dentro de los hogares, existe una tensión entre las formas tradicionales, que aún son preponderantes, ylos sistemas digitales, Youtube y Netflix entrelas principales

13 Véase: Ley No 1835 (2017), sancionada por el Congreso de la República de Colombia. Recuperado de: http://www. secretariasenado.gov.co/senado/basedoc/ley_1835_2017.html

14 Véase: Ley No 1978(2019), sancionada por el Congreso dela República de Colombia. Recuperado de: https://dapre. presidencia.gov.co/normativa/normativa/LEY\%201978\%20DEL\%2025\%20DE\%20JULIO\%20DE\%202019.pdf 
referencias. Asimismo, las asimetrías regionales en materia de infraestructura y posibilidades socioeconómicas establecen un acceso diferencial a Internet $y$, por lo tanto, en el consumo audiovisual digital, focalizado en las grandes ciudades y, desde el punto de vista etario, en el público juvenil (Bustamante Bohórquez et al., 2019). Según las cifras de una encuesta realizada por la CRC en el año 2019, el 96\% de los hogares cuenta con un televisor y el 33\% acceden a servicios OTT gratuitos, siendo Youtubela plataforma de mayor penetración con un $26 \%$. Por otrolado, el $24 \%$ de los encuestados tiene acceso a plataformas OTT pagas, lideradas por Netflix con un 17\%, seguida por Claro Video, HBO Go y DirecTV Play con el 3\%" (Comisión de Regulación de las Comunicaciones, 2020, p. 26). Los casos mencionados son ejemplos de la lenta migración hacia otras plataformas.

Frente a esta realidad, además de los servicios de streaming pagos ofrecidos por cableoperadores -Claro Video, DirectTV Play, entre ellos-, también existen esfuerzos recientes por parte de los canales abiertos, públicos y privados, para generar una oferta en la red, ya sea por streaming o a través del armado de repositorios digitales. La plataforma Caracol Play, por caso, funciona como un repositorio de contenidos lanzados en la televisión, pero también cuenta con material original estrenado directamente en la web, y en ambos casos existen contenidos gratuitos y otros que exigen el cobro por suscripción.

Por su parte, en el sistema de medios públicos, RTVC también tiene su propia plataforma, que además de funcionar como el archivo de distintas producciones colombianas emblemáticas de los años 80 , también contiene series, películas y documentales lanzados en televisión por el canal público Señal Colombia. Además, la plataforma RTVC Play cuenta con varios títulos creados y pensados para ser estrenados a través de la página web, como fue el caso de $E l$ Inquisidor, una serie de 2019 ficción hecha con dispositivos móviles que fue coproducida entreRTVCySmartFilms (Redacción RTVC, 30 de abril de 2020). Esta es, sin lugar a dudas, una de las muestras palpables de los lentos pasos de la industria audiovisual hacia la convergencia y la innovación en materia de generación de contenidos, aun cuando la televisión pública no ocupa los lugares de preferencia en el consumo de los colombianos.

Bustamante Bohórquezy otros autores (2019) plantean que el camino hacia la convergencia también puede evidenciarse a partir del surgimiento de nuevos actores y productoras independientes que han encontrado en YouTube un espacio de difusión prometedor. Lo cual se debe, fundamentalmente, al proceso que ha permitido aumentar la oferta y generar condiciones para la ampliación de la producción en el país. Un ejemplo de esto es la productora Dirty Kitchen, que ha realizado series web para distintas marcas y cuenta, además, con producciones originales que se distribuyen por YouTube y, de manera simultánea, circulan a través de sus cuentas en Instagram, donde paradójicamente tiene la mayor cantidad de seguidores, y Facebook. 
En ese marco de trasformaciones y en medio de la emergencia sanitaria que se vive desde hace más de un año, es probable que el consumo a través de plataformas OTT se haya incrementado, tal como lo indica el crecimiento de Netflix en el segundo trimestre del 2020, alcanzando más de 192 millones de suscriptores en todo el mundo (Redacción Forbes México (16 de julio de 2020) o la recién estrenada plataforma Disney+, que a principios de agosto alcanzó los 60,5 millones de suscriptores superando sus propias proyecciones de crecimiento (Solsman, 4 de agosto de 2020).

Un tal Alonso Quijano, producida por la Universidad Nacional de Colombia para UN Televisión (2020), y considerada la primera película estrenada en una plataforma digital y de manera gratuita durante la pandemia, es otro caso local que evidencia la transformación de la distribución de las producciones audiovisuales y su adaptación estratégica de acuerdo con la reacción de los usuarios (Redacción Vanguardia, 24 de junio de 2020; Redacción Cultura de El Tiempo (1 de julio de 2020). Aunque se tenía previsto que la película se mantuviera disponible del 1 al 15 de julio de 2020, la respuesta positiva de los usuarios hizo que se decidiera mantenerla de forma indefinida y, según los datos del 19 de agosto de 2020, alcanzó las 500.775 visualizaciones.

Finalmente, vale decir que este proceso de cambios se expresa en el Decreto No 474 de $2020^{15}$ por el cual se reglamentó el funcionamiento del Fondo Fílmico Colombia enmarcado en el Plan Nacional de Desarrollo, algo que se resume en el detalle conceptual de dejar de pensar en obras del "cinematográfico" y pasar a hacer referencia a la producción "audiovisual", lo cual incluye a la televisión, los videos musicales, las series web, la publicidad y los videojuegos como beneficiarios potenciales de los Certificados de Inversión Audiovisual que estimulan la producción local (Redacción Arcadia, 16 de junio de 2020).

\section{CONCLUSIONES}

El proceso de convergencia implica, necesariamente, una democratización de la esfera pública, que torna todo en un mito si se evidencia la concentración y el usufructo oligopólico de la producción y distribución audiovisual de los grandes medios o empresas ligadas al sector. Los cambios en la esfera audiovisual colombiana dan cuenta de los procesos de expansión y contracción que permiten observar políticas basadas en medios diferenciados, así como los límites de su aplicabilidad en el mundo audiovisual actual, ya que las medidas regulatorias que promovieron la producción cinematográfica se reconocieron finalmente estrechas para abarcar al cine, la televisión y el video. Al tiempo que su reconfiguración esconde el riesgo de una suerte de amalgama o convergencia que, a la par del desarrollo de las

15 Véase: Decreto № 474 (2020), Ministerio de Cultura, Presidencia de la República, Colombia. Recuperado de: https://dapre.presidencia.gov.co/normativa/normativa/DECRETO\%20474\%20DEL\%2025\%20DE\%20 MARZO\%20DE\%202020.pdf 
plataformas digitales, proyectan el sueño neoliberal de la expansión de las industrias creativas como gran paradigma de desarrollo económico (Arias, Uribe \& Miller, 2018).

En paralelo, y teniendo en cuenta los casos citados, el sistema de medios públicos busca entrar en el mundo de la multiplataforma, aunque la concentración de "un número muy limitado de personas en altas posiciones administrativas de gobierno" (Castaño, 2017, p. 217) y los límites que la regulación, por un lado, y la financiación de proyectos alternativos o de contenidos que no se asemejen a la producción privada, por el otro, también ha marcado una trayectoria irregular que aún requiere desarrollo y amplitud (García Ramírez, 2015).

En este marco, el espacio audiovisual ampliado en Colombia se ha configurado bajo un paradigma en donde convergen los distintos medios y los lenguajes audiovisuales (Uribe Jongbloed, 2016), pero expone un proceso de concentración que favorece a los grandes actores del campo, sean capitales extranjeros o nacionales. En tal sentido, la situación en Colombia ante los cambios en la producción y la distribución de los productos audiovisuales, y las transformaciones ligadas a su consumo, es muy similar a la que se exhibe en lugares como Argentina, ya que
la industria resuelve los cuestionamientos con su receta mágica y esperada: la concentración, donde el grande, con capacidad de sobrevivir se come al peque- ño y dependiente; y el Estado afronta la situación manteniendo mecanismos de fomento a la producción de contenidos para soportes diferenciados (cine, formatos de televisión abierta con ficciones de pocos capítulos, etc.) que no logran generar audiencias relevantes ni cumplir con las cuotas de diversidad esperada (Marino et al., 2016, p. 170).

Al mismo tiempo se exponen y continúan debates de larga data, como los presentados por los artistas desde los años 80 , que explicitan la precariedad laboral del sector, al punto de que las llamadas producciones fugitivas, que buscan condiciones que les permitan abaratar los costos de producción, se terminen convirtiendo, en algunos casos, en una suerte de "espejos" de condiciones dignas para los trabajadores locales. Como ya se ha mencionado, el incremento cuantitativo de producción cinematográfica y la expansión de la producción televisiva colombiana a través del servicio OTT no representa mejoras de las condiciones laborales existentes en Colombia (Uribe Jongbloed \& Corredor-Aristizábal, 2020; Castaño, 2017).

Finalmente, vale mencionar otro de los desafíos expuestos a partir de la sanción de la Ley No 1978, cuyo propósito sería modernizar las TICs y dejó en manos de la CRC garantizar el pluralismo y la diversidad en el contenido audiovisual de los canales de televisión, al igual que 
el desarrollo de la radiodifusión sonora pública, la televisión pública, la promoción de los contenidos multiplataforma de interés público que promuevan la preservación de la cultura y la identidad nacional y regional, y la apropiación tecnológica mediante el desarrollo de contenidos y aplicaciones con enfoque social $^{16}$.

En el entorno mediático contemporáneo las políticas de convergencia han resquebrajado las divisiones mediáticas clásicas y tienden a trasformar las potencialidades tecnológicas de producción, distribución y consumo. El riesgo es que su desarrollo no beneficie de manera equitativa a todos los sectores y agentes comprometidos en la producción local, sino que favorece a aquellos que disfrutan de una posición dominante, como es el caso de la producción audiovisual de Hollywood (Boyd-Barrett, 2015; Miller, 2020). El entorno digital, o "la nube", el espacio supuestamente etéreo que encapsula nuestros sueños de democracia, libertad y autocontrol a través de Internet (Mosco, 2014), descansa sobre grandes conglomerados económicos y espacios físicos cuyo flujo se encuentra a merced de los grandes operadores.

El espacio audiovisual ampliado que hoy nos atraviesa, nos forma, nos constituye, hace de esa existencia enmarañada y convergente -de ese espacio "de los libros que se leen, de la música que se oye, del cine que se ve y de los programas de televisión que divierten, informan, indignan, inquietan, aterran y entretienen" (Samper Pizano, 2004, p. 17)- un escenario central de las disputas contemporáneas.

\section{REFERENCIAS}

Anderson, B. (1983). Imagined Communities: Reflections on the Origins and Spread of Nationalism. London: Verso.

Arango Forero, G., Gutiérrez Coba, L., Forero Gutiérrez, A., Valderrama Valderrama, J., Prada Penagos, R., Barrera Avellaneda, L. C. \& Guzmán de Reyes, A. (2009). The Media in Colombia. In Albarran, A. (ed.), The Handbook of Spanish Language Media (pp. 63-76). London: Routledge.

Arias, O., Uribe, E. \& Miller, T. (2018). Colombia y el dilema clásico del apoyo cinematográfico. Revista Internacional de Comunicación y Desarrollo, 2(9), 115128. Recuperado de: https://doi.org/10.15304/ricd.2.9.5570

Banrepcultural (2020). La televisión en Colombia. Recuperado de: https://enciclopedia. banrepcultural.org/index.php/La_televisi\%C3\%B3n_en_Colombia\#El_ canal_11_y_la_televisi.C3.B3n_educativa_1970

16 Véase: Art. 3, Ley No 1978 (2019), sancionada por el Congreso de la República de Colombia. Recuperado de: https://dapre.presidencia.gov.co/normativa/normativa/LEY\%201978\%20DEL\%2025\%20DE\%20JULIO\%20 DE\%202019.pdf 
Benjamin, W. (1989). La obra de arte en la época de su reproductibilidad técnica. En Discursos interrumpidos (pp. 15-57). Madrid: Taurus.

Bernal, P. \& Dávila, G. (1999). El régimen jurídico de la televisión en Colombia. Bogotá: Pontificia Universidad Javeriana.

Boyd-Barrett, O. (2015). Media Imperialism. United State: Sage.

BustamanteBohórquez, B., Aranguen Díaz,F. \& RiverosSolórzano, H.(2019).Colombia: espacio de tensión entre la tradición y la digitalización. En Vasallo de Lopes, M. \& Orozco Gómez, G. (coordinadores), Modelos de distribución de la televisión por Internet: Actores, tecnologías, estrategias (pp. 145-177). Porto Alegre: Editorial Meridional.

Calero Aparicio, F. (2002). The Colombian media: modes and perspectives in television. En Fox, E. \& Waisbord, S. (eds.), Latin Politics, global media (pp. 89-106). United State: University of Texas Press.

Castaño, A. (2017).Media workandpublic value:Producingpublicservicetelevision under state control in Colombia. PhD Thesis, University of Leicester, United Kingdom.

Colprensa (19 de diciembre de 2016). Los Premios India Catalina renuevan su nombre. El Universal. Recuperado de: https://www.eluniversal.com.co/cultural/lospremios-india-catalina-renuevan-su-nombre-242760-HWEU351565

Comisión de Regulación de las Comunicaciones (2020). El rol de los servicios OTT en el sector de las comunicaciones en Colombia, 2019. Recuperado de: https://www. crcom.gov.co/uploads/images/files/CRC-EstudioOTT-2020-publicar-vf.pdf

Deuze, M. (2007). Convergence culture in the creative industries. International Journal of Cultural Studies, 10(2), 243-263. Recuperado de: https://dx.doi. org/10.1177/1367877907076793

Flew, T. \& Waisbord, S. (2015). The ongoing significance of national media systems in the context of media globalization. Media, Culture \& Society, 37(4), 620-636. Recuperado de: https://doi.org/ 10.1177/0163443714566903

Fox, E. \& Waisbord, S. (2002). Latin politics, global media. En Fox, E. \& Waisbord, S. (eds.) Latin Politics, globalmedia (pp.1-21). United State:University of Texas Press.

Fredriksson, M. (2020). Pirate utopia revisited. En Shimpach, S. (ed.), The Rourledge companion to global television (pp. 469-478). London: Routledge.

García Ramírez, D. (2015). El modelo de televisión regional en Colombia: canales públicos bajo los parámetros del mercado. Signo y Pensamiento, 34(66), 28-42. Recuperado de: https://doi.org/10.11144/Javeriana.syp34-66.mtrc

García, A. (2012). Televisión en Colombia: Surgimiento de los canales regionales. Luciérnaga, 4(7), 23-35. Recuperado de: https://doi.org/10.33571/ revistaluciernaga.v4n7a3 
Guzmán, J. (21 de octubre de 2018). Los secretos de "La estrategia del caracol”. El Tiempo. Recuperado de: https://www.eltiempo.com/cultura/cine-y-tv/los-secretos-dela-pelicula-la-estrategia-del-caracol-que-cumple-25-anos-283604

Habermas, J. (1990). Strukturwandel der Öffentlichkeit: Untersuchungen zu einer Kategorie der bürgerlichen Gesellschaft. Berlin: Suhrkamp.

Jenkins, H. (2006). Convergence culture: where old and new media collide. New York: University Press.

Kellner, D. (2020). Critical perspectives on television from the Frankfurt school to the politics of representation. En Wasko, J. \& Meehan, E. (eds.), A companion to television (pp. 17-37). United State: Wiley Blackwell.

Kit, B. (2020). “It Will Be an Entirely New Thing”: Zack Snyder’s \$20M-Plus 'Justice League' Cut Plans Revealed. The Hollywood Reporter. Recuperado de: https:// www.hollywoodreporter.com/heat-vision/justice-league-snyder-cut-plansrevealed-it-will-be-an-new-thing-1295102

Lobato, R.(2010).Creativeeconomies andinformaleconomies:lessonsfrom Nollywood. International Journal of Cultural Studies, 13(4), 337-354.

Marino, S. (2016). Argentina en el periodo de tránsito hacia el espacio audiovisual ampliado. En Marino, S. (coord.), El audiovisual ampliado (pp. 11-13). Ediciones Universidad del Salvador.

Marino, S., Linares A., Páez Triviño, A., Labate, C., Di Santi, M. \& Riera, A. (2016). Palabras finales. En Marino, S. (coord.), El audiovisual ampliado (pp. 169-172). Ediciones Universidad del Salvador.

Matías, S. (2006). Políticas públicas y telecomunicaciones en Colombia. Diálogos de Saberes (24), 13-31.

Mattelart, A. \& Mattelart, M. (1997). Historia de las Teorías de la Comunicación. Barcelona: Paidós.

Mattelart, T. (2009). Audio-visual piracy: towards a study of the underground networks of cultural globalization. Global Media and Communication, 5(3), 308-326.

McLuhan, M. (1994). Comprender los medios de comunicación: Las extensiones del ser humano. Barcelona: Paidós.

Mejía Reyes, A. (2006). Historia de la televisión por cable en Colombia en el periodo 1985-2005. Trabajo final de grado, Universidad de los Andes, Bogotá, Colombia.

Miller, T. \& Kraidy, M. (2016). Global media studies. Cambridge: Polity Press.

Miller, T. (2020). El trabajo cultural. Barcelona: Gedisa. 
Ministerio de Cultura (2010). Compendio de Políticas Culturales. Bogotá: Ministerio de Cultura. Recuperado de: https://www.mincultura.gov.co/areas/fomentoregional/Documents/Compendio-Pol\%C3\%ADticas-Culturales.pdf

Mosco, V. (2014). La Nube. Barcelona: Biblioteca Buridán.

Obiaya, I. (2012). Behind the scenes: working conditions of technical workers in the Nigerian film industry. In Dawson, A. \& Holmes, S. P. (eds.), Working in the global film and television industries (pp. 109-120). New York: Bloomsbury Academic.

Pacheco, R. (2015). La Autoridad Nacional de Televisión, ¿una agencia estatal independiente? RevistaDigitaldeDerechoAdministrativo (13),63-98. Recuperado de: https://doi.org/10.18601/21452946.n13.06

Pardo, D. (5 de julio de 2019). Qué cuenta la serie de Netflix sobre Simón Bolívar y por qué Madurola calificó de "basura". BBCMundo. Recuperado de: https://www.bbc. com/mundo/noticias-america-latina-48872861

Presidencia de la República, Colombia (2018). Bases del Plan Nacional de Desarrollo 2018-2020. Recuperado de: https://id.presidencia.gov.co/especiales/190523PlanNacionalDesarrollo/documentos/BasesPND2018-2022.pdf

Proimágenes Colombia (2020). Cine en Cifras. Newsletter, 19. Recuperado de: http:// www.proim.agenescolombia.com/secciones/cine_colombiano/cine_en_cifras/ cine_cifras_listado.php

Redacción Arcadia (16dejuniode2020).96 mil millones depesos máspara elaudiovisual en 2020. Semana. Recuperado de: https://www.revistaarcadia.com/cine/ articulo/96-mil-millones-de-pesos-mas-para-el-audiovisual-en-2020/81939

Redacción Caracol Radio (26 de septiembre de 2018). Netflix con la primera serie colombiana, "Distrito Salvaje". Caracol Radio. Recuperado de: https://caracol. com.co/radio/2018/09/26/cultura/1537984308_219864.html

Redacción Cultura de El Tiempo (1 de julio de 2020). "Un tal Alonso Quijano", película sobre un Quijote que se verá gratis. El Tiempo. Recuperado de: https://www. eltiempo.com/cultura/cine-y-tv/pelicula-colombiana-un-tal-alonso-quijanose-exhibira-gratis-512838

Redacción El Espectador (9 de septiembre de 2011). Netflix llega a Colombia. El Espectador. Recuperado de: https://www.elespectador.com/noticias/tecnologia/ netflix-llega-a-colombia/

Redacción El Tiempo (11 de junio de 2004). 50 años de la televisión. El Tiempo. Recuperadode:https://www.eltiempo.com/archivo/documento/MAM-1528964

Redacción El Tiempo (16 de diciembre de 1990). Aprobado nuevo estatuto para la TV.El Tiempo. Recuperado de:https://www.eltiempo.com/archivo/documento/MAM39783 
Redacción Forbes México (16 de julio de 2020). Ingresos de Netflix crecen 25\% pero prevén lento cierre de 2020. Forbes México. Recuperado de: https://www.forbes. com.mx/negocios-ingresos-netflix-cierre-2020/

Redacción Gov.Co (25 de julio de 2019). Presidente Duque sancionó la Ley de Modernización delsector TIC. Recuperado de: https:/www.mintic.gov.co/portal/ inicio/Sala-de-Prensa/Noticias/101905:Presidente-Duque-sanciono-la-Ley-deModernizacion-del-sector-TIC

Redacción La Vanguardia (18 de agosto de 2020). La primera cinta de Harry Potter logra mil millones de dólares en taquilla, veinte años después. La Vanguardia. Recuperado de: https://www.lavanguardia.com/cine/20200818/482905360153/ harry-potter-y-la-piedra-filosofal-mil-millones-dolares-veinte-anos-despuescoronavirus.html

Redacción Publimetro Colombia (19 de julio de 2019). La llamada que hizo Andrés Pastrana para cambiar el destino de "Betty, la Fea". Publimetro. Recuperado de: https://www.publimetro.co/co/entretenimiento/2019/07/18/dia-andrespastrana-intervino-cambiar-destino-betty-la-fea.html

Redacción Radio Nacional de Colombia (13 de junio de 2019). Actores colombianos ya cuentan con ley que les da garantías laborales. Recuperado de: https://www. radionacional.co/noticia/senado/actores-colombianos-ya-cuentan-ley-que-lesda-garantias-laborales

Redacción RTVC.Sistema de medios públicos(30 de abrilde2020).SmartFilmsy RTVC preparan segunda temporada de "El Inquisidor". Gov.Co. Recuperado de: https:// www.rtvc.gov.co/noticia/smartfilms-y-rtvc-preparan-segunda-temporada-deel-inquisidor

Redacción Vanguardia (24 dejunio de 2020). “Un Tal Alonso Quijano”,la nueva película de la santandereana Libia Stella Gómez, en estreno gratis y digital. Vanguardia. Recuperado de: https://www.vanguardia.com/entretenimiento/cultura/un-talalonso-quijano-la-nueva-pelicula-de-la-santandereana-libia-stella-gomez-enestreno-gratis-y-digital-EE2530996

Redacción W Radio (1 de agosto de 2019). Ana María Orozco: "Nosotros nunca hemos recibido regalías por Betty, la fea": W Radio. Recuperado de: https://www.wradio. com.co/noticias/sociedad/nosotros-nunca-hemos-recibido-regalias-por-bettyla-fea-ana-maria-orozco/20190801/nota/3935037.aspx\#

Rivera Betancur, J. (2014). ¿Va el cine colombiano hacia su madurez? Análisis de 10 años de ley de cine en Colombia. Anagramas, 13(25), 127-144.

Rivera Betancur, J. (2019). El papel del cine colombiano en la escena latinoamericana. Chía, Colombia: Universidad de La Sabana.

Rivera, M. (10 de agosto de 2020,). ¿Qué está en juego con el estreno de "Mulan" en plataformas digitales? Shock. Recuperado de: https://www.shock.co/cine-y-tv/ que-esta-en-juego-con-el-estreno-de-mulan-en-plataformas-digitales-ie10266 
Roncallo-Dow, S. (2019). The south is the message: Media ecology reception and perspectives in Latin America. In Preciado, A. (ed.), Media ecology: A field of study (pp. 71-88). Chía, Colombia: Universidad de La Sabana.

Rubin, R. \& Davis, R. (2020). Christopher Nolan's 'Tenet' Lands September Debut in China. Variety. Recuperado de: https://variety.com/2020/film/box-office/tenetchina-release-date-christopher-nolan-1234727515/

Samper Pizano, D. (2004). ¿ Hay vida más allá de la televisión? En Amaral Ceballos, D. (comp.), 50 años. La televisión en Colombia: una historia para el futuro (pp. 15-17). Bogotá: Caracol Televisión.

Scolari,C.(2013a).Delastablillasalas tablets: evolución deloseMagazines. Elprofesional de la Información, 22(1), 10-17.

Scolari, C. (2013b). La televisión, los libros y la feria: si no puedes vencerlos, únete a ellos (y pásate al transmedia). En Orozco, G. (Coord.), TV Morfosis 2: convergencia y escenarios para una televisión interactiva (pp. 27-35). Ciudad de México: Tintable.

Señal Memoria. Redacción RTVC. Sistema de medios públicos (2 de agosto de 2018) ¿Cómo sehacíala televisión en Colombia en 1958? Gov.Co. Recuperadode:https:// www.senalmemoria.co/articulos/como-se-hacia-la-television-en-colombiaen-1958

Solsman, J. (4 de agosto de 2020). Disney Plus alcanza los 60.5 millones de suscriptores. CNET. Recuperado de: https://www.cnet.com/es/noticias/disney-plus-alcanzalos-60-5-millones-de-suscriptores/

Tenorio, J. (2017). El estado y el fomento del cine colombiano. Cuadernos de Cine colombiano, (26), 11-25.

Triana de Vargas, C. (1982). Gustavo Nieto Roa. Cuadernos de Cine colombiano, (6), 3-6.

Uribe Jongbloed, E. \& Corredor-Aristizábal, M. A. (2020). Creative industries policies and conditions of cinema labor in Colombia in the 21 st century. Creative Industries Journal, 3(13). Recuperado de: https://doi.org/10.1080/1 7510694.2019.1709016

Uribe Jongbloed, E. \& Diez, P.E. (2017). The TV format market in Latin America: trends and opportunities. International Journal of Digital Television, 1(8), 99-115.

Uribe Jongbloed, E. \& Miller, T. (2020). After or back to Third Cinema? Plebeian film, the national popular, fingernails and the resilient behemoth. In Mazierska, E \& Kristensen, L. (Eds.), Third Cinema, World Cinema and Marxism (pp. 273-289). London: Bloomsbury.

Uribe Jongbloed, E. (2016). El cambio mediático de la televisión: Netflix y la televisión en teléfonos inteligentes. Palabra Clave. 19, 358-364. Recuperado de: 10.5294/ pacla.2016.19.2.1. 
Mora-Moreo, C., Uribe-Jongbloed, E. \& Puccini Montoya, A. (2014).Entrevista a Carlos Benjumea, 13/09/2014.

Mora-Moreo, C., Uribe-Jongbloed, E. \& Puccini Montoya, A. (2016).Entrevista a Daniel Samper Pizano, 20/01/16.

Vallejo, A. (2018). Ernesto Contreras: "Para mí las series han sido toda una revelación”. Estudios Cinematográficos, (1), 124-130.

Vizcaíno, M. (2004). La legislación de televisión en Colombia: entre el estado y el mercado. Historia Crítica, (28), 127-151.

\section{MATERIAL AUDIOVISUAL CITADO}

Amuchastegui, K. \& Rivillas, M. (1987). Don Camilo. Colombia: Coestrellas.

Cabrera, S. (1993). La estrategia del caracol. Colombia: FOCINE, Caracol Televisión, Fotograma S.A.

Canal RCN (1999). Yo soy Betty, la fea. Colombia: RCN Televisión.

Caracol Play (2013). Anuncio del portal Caracol Play [Archivo de video]. Recuperado de: https://www.youtube.com/watch?v=BpHhQ2epr-k

Caro,N.(2020).Mulan.Estados Unidos: WaltDisney Pictures, JasonTReed Productions, Good Fear Content.

Columbus, C. (2001). Harry Potter and the Philosopher's Stone. Warner Bros, Heyday Films, 1492 Pictures.

Cuarón,A. (2018). Roma.Cuarón, A. (2018).Roma. México-Estados Unidos:Participant Media, Esperanto Filmoj y Netflix.

Gaviria, V. (1990). Rodrigo D: No futuro. Colombia: FOCINE, Producciones Tiempos Modernos.

Gaviria, V. (1998). La vendedora de rosas. Colombia: Filmamento.

Nieto Roa, G. (1979). El taxista millonario. Colombia: Centauro Films, Cine Colombia.

Nolan, C. (2020). Tenet. Reino Unido-Estados Unidos: Syncopy Prduction, Warner Bros.

UN Televisión (2020). Un tal Alonso Quijano. Colombia: Universidad Nacional de Colombia.

Whedon, J. \& Snyder, Z. (2017). Justice League. Estados Unidos: Warner Bros. 
${ }^{\star}$ Contribución: el artículo fue realizado conforme a criterios equitativos de trabajo.

* Nota: el Comité Editorial de la revista aprobó la publicación del artículo.

\section{(c) $B Y$}

Artículo publicado en acceso abierto bajo la Licencia Creative Commons - Attribution 4.0 International (CC BY 4.0).

\section{IDENTIFICACIÓN DE LES AUTORES}

César Mora Moreo. Comunicador Social y Periodista, Universidad del Norte (Colombia). Co-investigador del proyecto "Condiciones y expectativas de los trabajadores del audiovisual a partir de la Ley 1556", seleccionado por el Fondo de Desarrollo Cinematográfico (Colombia), en la categoría Investigación en Cinematografía, 2019. Autor de la novela Al final, el océano (2019), ganadora del Premio de Novela Distrito de Barranquilla (Colombia).

Alessandra Puccini Montoya. Comunicadora Social y Periodista, Universidad Externado (Colombia). Miembro del proyecto de investigación "Sello latinoamericano para la exportación de ficción televisiva: Mercado, comunicación y experiencia en la era del streaming”, Universidad Federal de Minas Gerai (Brasil) y del Grupo Recasens de Investigación en Comunicación (Colombia).

Enrique Uribe Jongbloed. Doctor en Medios y Comunicación, Universidad de Aberystwyth (Reino Unido). Magister en Patrimonio Cultural, Brandenburgische Technische Universität Cottbus (Alemania). Docente e Investigador, Universidad Externado (Colombia). Miembro, Grupo Recasens de Investigación en Comunicación (Colombia). Investigador principal del proyecto Condiciones y expectativas de los trabajadores del audiovisual a partir de la Ley 1556, seleccionado por el Fondo de Desarrollo Cinematográfico (Colombia), en la categoría Investigación en Cinematografía, 2019. Coinvestigador del proyecto "Sello latinoamericano para la exportación de ficción televisiva: Mercado, comunicación y experiencia en la era del streaming”, Universidad Federal de Minas Gerai (Brasil). 
(N) 